\title{
1. FAULTING AND FLUID FLOW IN ACCRETED SEDIMENTS: HOLE 863B, CHILE TRIPLE JUNCTION ${ }^{1}$
}

\author{
Susan M. Agar ${ }^{2}$ and David J. Prior ${ }^{3}$
}

\begin{abstract}
The faults in the "steeply dipping" domain of Hole 863B are situated in a distinct tectonic setting, where an active spreading center is subducting. Early rheological contrasts, arising from primary compositional differences, were enhanced by fluid flow channeled along bedding planes. Several early faults localized under low effective stresses, parallel to bedding planes. Fluid flow was focused along discrete millimeter to centimeter-scale, branching channels within fault zones and their surroundings, even though the sediments were only partially consolidated. Individual core-scale fault zones accommodate only minor strain but they contain penetrative grain-scale fabrics. These fabrics were generated during a dilation-fluid flow-porosity collapse history, interpreted from textural variations and cross-cutting relations in fault zones. There is no evidence for cataclasis or pressure solution in fault rocks but some dissolution has occurred. A generalized sequence of cementation is represented by early sulfate and clay minerals and zeolites followed by pyrite, carbonate and minor quartz. Carbonate and pyrite cements formed prior to and synchronously with normal faults. Normal faults generally post-date reverse faults and could be related to ridge subduction. The interpreted deformation and cementation histories illustrate the fine-scale porosity (and permeability?) variations caused by linked cementation and deformation in the earliest stages of accretion.
\end{abstract}

\section{INTRODUCTION}

The architecture of the front of accretionary prisms is strongly influenced by failure mechanisms that accommodate the deformation of partially consolidated sediments. Studies of exhumed forearcs have highlighted the importance of pore-fluid pressure variations that, together with other environmental parameters, cause variations in the timing and location of failure and associated deformation mechanisms. Several onshore studies have illustrated the heterogeneous strain resulting from variable cementation rates and compositions in accreted slope and trench sediments (Cowan, 1985; Fisher and Byrne, 1987; Pickering et al., 1990; Agar, 1990). Field and experimental investigations have highlighted variations in porosity and permeability that are generated during deformation and the feedback of deformation on these physical properties (Shephard and Bryant, 1983; Bray and Karig, 1985; Karig, 1990; Arch and Maltman, 1990). Microstructural studies have also yielded valuable insights to the nature of polyphase fluid flow and deformation in ancient accretionary complexes (Fisher and Byrne, 1990; Sample and Fisher, 1986; Agar, 1990). The relationship of diagenesis to early deformation, however, is commonly obscured by subsequent metamorphism and deformation.

Ocean Drilling Program Site 863, located at the toe of the Chile Triple Junction accretionary complex, provides an unusual opportunity to examine the nature of fluid flow and deformation in the earliest accretion phases. Drilling in other accretionary complexes has provided microstructural data from similar prism locations (e.g., Lundberg and Moore, 1986; Kemp, 1990 [Peru Margin]; Brown and Behrmann, 1990 [Barbados]; Maltman et al., 1993; Byrne et al., 1993 [Nankai]). The Chile Triple Junction, however, represents a distinct tectonic setting where the impact of a subducting, active spreading center can be assessed. Using microstructural data from faulted sediments in Hole 863B, we present examples of deformation and cementation histories and discuss the temporal and spatial relationships among fault microstructures, failure mechanisms, and fluid flow.

'Lewis, S.D., Behrmann, J.H., Musgrave, R.J., and Cande, S.C. (Eds.), 1995. Proc. $O D P$, Sci. Results, 141: College Station, TX (Ocean Drilling Program).

${ }_{2}^{2}$ Geological Sciences Dept., Northwestern University, Evanston, IL 60208, U.S.A.

${ }^{3}$ Earth Sciences Dept., Liverpool University, Liverpool L69 3BX, United Kingdom.

\section{TECTONIC FRAMEWORK AND OVERVIEW OF HOLE 863B}

Hole $863 \mathrm{~B}$ is sited at the base of the Chile Trench slope, about 2 $\mathrm{km}$ east-northeast of the frontal thrust of the prism. A strong reflector, which lies about $1 \mathrm{~km}$ below the surface on seismic images across Site 863 , is interpreted as the axial zone of the subducting Chile Ridge. Several eastward-dipping reflectors to the east of this strong reflector have been identified as accretion-related thrusts (Cande et al., 1987). The ridge/transform intersection of the Taitao Fracture Zone lies about $20 \mathrm{~km}$ to the south.

Four structural domains have been identified within core from Hole 863B (Behrmann, Lewis, Musgrave, et al., 1992). This paper focuses on faults in the lowest structural domain, located between 258.8 and $742.9 \mathrm{~m}$ below seafloor (mbsf). Lithologies in this "steeply-dipping" domain comprise the lower section of lithologic Unit II (104.4-742.9 mbsf), represented by a sequence of upper and lower Pleistocene sandstone and bioturbated siltstone with sandy-silty claystone (Behrmann, Lewis, Musgrave, et al., 1992). Some individual, steeply dipping layers can be traced for over $2 \mathrm{~m}$. The upper limit of steeply dipping turbidites is marked by a thrust zone, located between $290-325$ mbsf, which has emplaced lower Pleistocene over upper Pleistocene sediments. The deformation history recorded by core microstructures is therefore post-Pleistocene. Authigenic opaque minerals, zeolite and clay cements and framboidal pyrites were precipitated during the diagenesis of Unit II. Carbonate cements are also volumetrically significant, particularly in coarse sandstones. Dissolution of amphibole and pyroxene, and micritization of nannofossils accompanied cementation (Prior et al., this volume). An overall temperature gradient of $85^{\circ} \mathrm{C} / \mathrm{km}$ is estimated for the borehole and diagenesis is more pronounced with depth (Behrmann, Lewis, Musgrave, et al., 1993).

Fault zones in Hole 863B were interpreted from intervals of broken formation, slickenlines, and foliated clays (Behrmann, Lewis, Musgrave, et al., 1992). Dense arrays of "deformation bands" (or microfaults) are found predominantly lower in the core but both carbonate veins and deformation bands are more prevalent in zones interpreted as major faults (e.g., $687 \mathrm{mbsf}$ ). Core observations suggest that normal faults consistently overprint reverse faults in the "complexly faulted" domain (3.3-46.6 mbsf). A strike-slip component of motion has been inferred from the obliquity of reoriented 
bedding and fault orientations relative to the margin and plate convergence vector (Behrmann, Lewis, Musgrave, et al., 1992).

\section{MICROSTRUCTURAL ANALYSIS}

Polished thin sections and blocks of specimens were examined optically and under secondary and backscatter electron imaging (BSE) on a JEOL 733 Superprobe. Samples were cut on a micro-annular saw in paraffin. Where necessary, samples were impregnated with very low-viscosity resin. This avoided the need for vacuum impregnation and possible disruption of sediment fabrics resulting from forced resin penetration. Samples were polished initially with diamond grit and paste and finally, where feasible, with colloidal silica on a polyurethane-covered lap. Electron imaging and qualitative energy dispersive $\mathrm{X}$-ray analyses were performed at $15 \mathrm{kV}$ and working distances of 11 $\mathrm{mm}$. Samples were also examined under cathodoluminescence. $\mathrm{Ob}$ taining a high-quality polish on the weakly consolidated sediments was difficult and limited the resolution of BSE imaging. Sediment fabrics, however, still clearly could be distinguished.

The term "deformation band" was used during initial core description to refer to a planar or curviplanar feature recognized in the core as a seam or seams of a different color or grain size and attributed to deformation. This term included features with an observable separation that could be also termed faults. We restrict the use of deformation band in this paper to such features where no displacement can be determined. The microstructures discussed here are located in zones identified as faults during initial core description. We use the term "fault" to refer to any discrete planar break showing a displacement at any scale.

\section{FAULT ZONE CHARACTERISTICS}

The faults in the steeply dipping domain have predominantly moderate to steep dips although there is a wide range in dips overall (see Site 863, Structural Geology section, Fig. 44, Behrmann, Lewis, Musgrave, et al., 1993). Many of the steep faults have localized along the steeply-dipping bedding planes. The shear sense on some faults can be determined from preserved offsets in bedding or laminations, and steps in slickencrysts. Changes in thickness of identified units across faults may indicate a strike-slip component of displacements, as suggested by core-scale observations (Behrmann, Lewis, Musgrave, et al., 1993). Although the sample size limits a maximum estimate for displacements, offsets range from submillimeter to about $1 \mathrm{~cm}$ vertical displacement. Several kinematic indicators provide supporting evidence for shear sense and are discussed below. A broad spectrum of fault microstructures in oblique, normal, and reverse faults is present in the Hole $863 \mathrm{~B}$ core samples. The principle characteristics that vary within this spectrum are (1) fault zone width, (2) geometries of microstructural domains within the fault rock, (3) the extent of wall rock disaggregation, (4) subsidiary fracturing and faulting in the wall rock, and (5) injection of external or locally derived material along the fault zone.

Individual fault widths vary from submillimeter to greater than 1 $\mathrm{cm}$ (Pls. 1-5). The broader sections of fault zones $(0.3$ to $1 \mathrm{~cm})$ are generally characterized by more extensive wall rock disaggregation and mixing and do not display laterally consistent penetrative fabrics (over several $\mathrm{cm}$ ). Within the fault rock discrete microstructural and compositional domains can also be identified (see "Fault Rock Fabrics" section below) (Pl. 1). The narrow sections of faults (about 0.5 up to $3 \mathrm{~mm}$ wide) have discrete junctions with the wall rock, commonly parallel or subparallel to the steeply dipping bedding. Many such faults have been localized by lithological contrasts (Pl. 2, Figs. 1 and 2). Microstructural and compositional domains are preserved in some narrow sections of faults but these typically have simpler geometries than those associated with broader zones and are more laterally persistent. For example, in Sample 141-863-16R-4, 134-136 cm, three distinct fault-parallel domains, each about $500 \mu \mathrm{m}$ wide can be distinguished by their contrasting cementation, grain alignment, and grain size (Pl. 2). Discrete narrow faults occur as networks of subsidiary faults in the footwall or hanging wall of broader fault zones, together with deformation bands (planar, dark zones in hand specimen). They also occur as discrete continuous faults across entire core sections (Pl. 3, Fig. 1) with hairline splay faults and fractures penetrating the wall rock.

The degree of subsidiary faulting in the footwall and hanging wall of broader faults varies. In some examples no microstructural disturbance can be detected whereas in others bedding is deformed by numerous minor faults and in places is warped by rotation into the fault.

Some faults are associated with "wet sediment" injections where silt- and clay-sized grains, together with fossil fragments have been transported along narrow fractures (also termed deformation bands). These fractures vary in width from $100 \mu \mathrm{m}$ to $1 \mathrm{~mm}$ (Pl. 2). Some of the mud-filled fractures are discontinuous with overlapping, curved fracture terminations. Silt and clay injections penetrate and disrupt the wall rock (from 1 to $3 \mathrm{~mm}$ on either side of faults). Fragments of the wall rock isolated by the mud invasion have also been incorporated into and transported along the fault zone (Pl. 2).

\section{FAULT ROCK MICROFABRICS}

The components of fault rock fabrics can be broadly divided into (1) zones of penetrative preferred grain alignment, (2) zones of preferred orientation defined by shape fabrics of grains within sediment lenses or vein, cement or fossil fragments, (3) discrete veins of clastic material or cement phases (4) open fractures. Some or all of these features are found in individual fault zones and are not uniquely associated with one fault generation or shear sense type. Associated variations in porosity and mineralogy occur both across and along faults.

\section{Zones of Preferred Grain Alignment}

Where sediment grains have inequant shapes they are commonly aligned either subparallel to the margins of the fault or in domains with internal grain alignments oblique to the fault zone margins (e.g., PI. 1 and PI. 3, Figs. 2 and 4). For example, in Sample 141-863B-16R$4,81-85 \mathrm{~cm}$, within a 1-cm-wide shear zone, some larger clasts (longer than $1 \mathrm{~cm}$ ) have been rotated parallel to the fault zone walls. Coarse sand grains, fossil tests, and large detrital chlorite books display a moderate preferred orientation within locally derived sediments or injected silty-clay matrix (Pl. 2 and Pl. 4, Fig. 6). 100- $\mu$ mwide anastomosing zones that are oriented subparallel to the fault zone margins contain regions of preferred grain alignment, corresponding to variations in BSE intensities. The anastomosing pattern is most pronounced in sections perpendicular to the vertical core axis and may result from oblique displacements.

The degree of preferred alignment varies across faults, intensifying locally (PI. 3), but is more laterally persistent than the preferred alignments noted in deformation bands from Site 860 (Rochford et al., this volume). Fry plots (Fry, 1979) of aligned clastic grains within such domains indicate a low strain with the average 2-dimensional strain ratio of about $1: 1.5$ with the maximum principal elongation oriented parallel to the fault (e.g., Pl. 3, Fig. 4). The injection of fine grained material along some fault zones and the rotation of clasts during dilation may however limit the reliability of these strain estimates.

A reduction in grain size relative to the surrounding domains accompanies grain alignment in some of these regions (PI. 3, Fig. 2). In several fault zones, $\mathrm{X}$-ray dot maps indicate that these regions are enriched in calcium and iron. A higher mean atomic number indicated by an overall increase in BSE brightness in some of these regions suggests a reduction in porosity. An increased consolidation state relative to the surrounding rock may also be indicated by the fact that these zones are less easily damaged during specimen preparation (Pl. 3, Figs. 2, 4 and 5).

Preferred grain shape orientations are not restricted to the main fault zones. Within the hanging and footwalls of faults, narrow $(50 \mathrm{~m})$, 
branching zones are defined by a weak preferred orientation of grains that also appear brighter on BSE images. The distribution and geometries of these structures closely resemble those of "web structures" (Cowan, 1982) but there is no evidence for cataclasis or pressure solution overprints (e.g., Lucas and Moore, 1986; Agar, 1990).

\section{Alignment and Asymmetry of Sediment Lenses and Cement or Vein Fragments}

In addition to grain-scale fabrics, sediment lenses, cement and vein fragments also exhibit shape-preferred orientations. Where bedding or laminations have been disrupted by faulting, layers have been dismembered into lenses, similar to the mesoscopic "pinch and swell" structures found in broken formations (Pl. 1, Fig. 1). In some cases the sigmoidal lenses have formed by deflection of fractured laminae into numerous, closely spaced normal faults within a broader fault zone (Pl. 1, Fig. 1). The asymmetry of these lenses indicates either drag into the main fault or strain within the footwall or hanging wall of the fault. In other cases, lenses of silt or sand have formed within a fault zone and shape changes have been accommodated by grainboundary sliding. Ghost laminae preserved in sediment lenses are offset between different lenses suggesting that the lenses have acted semicoherently, sliding over one another during failure. Such zones may represent precursors of "scaly fabric" where no grain scale fabric is present but a closely spaced foliation is observed in hand specimen (Moore et al., 1986; Agar et al., 1989; Prior and Behrmann, 1990). Within silt and fine-sand lenses there is no shape-preferred orientation of clastic grains and porosity is commonly increased relative to similar lithologies removed from the fault (Pl. 1, Figs. 1 and 2). Fragments of carbonate veins are commonly dismembered into subangular fragments that have rotated on minor faults to generate a shape asymmetry (Pl. 1, Figs. 1 and 3 ).

\section{Veins}

Carbonate veins and pyrite stringers are present as pre-, syn- and post-fault structures (see below). Some pre-fault veins, including a hydrous sulfate phase, carbonate and pyrite, were localized along sediment horizons. Several such veins are truncated and locally folded or rotated by reverse and normal faulting (PI. 5). Intergranular patches of carbonate cement, developed in coarser sandstone fractions, are commonly linked to carbonate veins. We have not found zeolites as discrete fracture-fill phases but hydrous sulfate phases occur in narrow (less than $100 \mu \mathrm{m}$ ), planar and weakly anastomosing cementation zones in both fault zones and the wall rocks. We interpret these features as dilation zones in which an increased permeability has enhanced fluid flow and cementation without generating a discrete fracture. No offsets have been quantified along these focused fluid-flow zones, which closely resemble "ghost veins" described by Kemp (1990).

Synkinematic carbonate veins are present either as thin, discontinuous veins parallel to the margins of normal faults or as en echelon arrays, $100-500 \mu \mathrm{m}$ wide (Pl.1, Fig. 3, Pl. 3, Fig. 5, and Pl. 4, Fig. 3). The local opening direction indicated by veins within these arrays is compatible with the shear sense inferred from other displacement markers (e.g., Pl. 1, Fig. 3). Some veins comprise three or four subparallel layers of carbonate (10-50 $\mu \mathrm{m}$ wide) separated by stringers of sediment. No shape preferred orientation of calcite grains or fibers are evident. Although pyrite is dispersed throughout the sediment (see Prior et al., this volume) some pyrite stringers have also been found in en echelon arrays oblique to shear zone margins.

\section{Sediment Injections}

Sediment lenses and vein fragments are commonly separated by undeformed silt or clay grains, injected at high angles across fault zones and bedding (Pl. 5, Figs. 1-3, Pl. 1, Fig. 1, and Pl. 4, Fig. 2). These mud injections were synchronous with the deformation of cemented material, indicating fine-scale cementation heterogeneities.
Sand injections also occur as minor structures within faults where the margins of sand filled "veins" are oriented perpendicular to the local extensional direction of the shear couple, as inferred from other fault displacement indicators. Fluid-flow rates accompanying these injections may have influenced local variations in bulk fault rock composition. For example, in Sample 141-863B-16R-4, 134-136 cm, a poorly sorted silty sandstone has disaggregated close to the fault but clay-size fragments are concentrated within the fault zones (or deformation bands). This may indicate that the fluid-flow velocities were sufficient only to transport smaller clasts.

\section{Open Fractures}

Thin section preparation may have induced artifacts into the microfabrics of the Hole 863B samples, but there is a close correlation with open-fracture spatial distribution and fabrics described above. For example, where there is a strong preferred phyllosilicate alignment the spacing of open fractures correspondingly decreases, both within faults and in weakly deformed zones in the wall rock (Pl. 4, Fig. 5). We interpret these open fractures as local stress-release cracks. Although these cracks were probably generated during and after core recovery, their close spatial correlation with fabrics suggests that they may provide some indication of differential consolidation in the Hole 863B sediments (Prior and Behrmann, 1990).

\section{FAILURE MECHANISMS AND POROSITY EVOLUTION}

Transient dilation events during faulting are suggested by the alignment of clastic grains within domains in fault zones without any penetrative grain-scale deformation. The lack of penetrative grainscale deformation indicates that shape-preferred orientation fabrics were generated by the rotation of grains during independent particulate flow (Borradaile, 1981). Synfault, bulk disaggregation of the wall rock and localized deformation of silt and sand lenses also generated zones of enhanced porosity. Transient fracture porosity within the faults is also illustrated by synkinematic calcite veins and sand veins.

The loss of porosity in phyllosilicate-rich zones probably resulted from differential compaction during and after slip in which the grain alignment resulted in closer packing during consolidation. An increased proportion of clay minerals resulting from injection of fine detrital grains along the fault may have promoted the alignment and consolidation. The coincidence of the grain-size reduction with no change in bulk composition but an increased preferred orientation may indicate local dissolution during fluid flow. There is no clear evidence for grain size reduction by pressure solution although the textural evidence for low effective stresses and low strain rates would favor this mechanism. TEM studies are needed for these fine-grained zones. Hole $863 \mathrm{~B}$ is unusual in the lack of penetrative grain-scale deformation. Studies in other accretionary complexes have reported cataclasis at shallow depths (Lucas and Moore, 1986), but only rare intragranular cracking is present at Hole 863B.

Models for faulting in partially consolidated sediments have appealed to syndeformation dilation as a permeability enhancement process allowing fluids to flow along fault zones (Knipe, 1986a and b; Knipe et al., 1990). Primary rheological contrasts, controlled by changes in detrital mineralogy across bedding planes, were probably enhanced by early heterogeneous cementation. Early permeability along bedding planes may also have been influenced by local deviatoric stresses resulting from the heterogeneous compaction of wet sediments. We suggest that in the early stages of deformation fluids in the Hole 863 sediments migrated along permeable zones between strata. Reverse and normal faulting localized along bedding planes where effective stresses were reduced by the presence of intergranular fluid. At the same time, dewatering by ghost veins occurred at high angles to bedding. 
The variations in fabric domains and their cementation suggest partitioning of fluid flow during deformation. Our observations suggest that even within narrow fault zones, there can be both discrete channels and other domains of unaligned clasts. We interpret the zones of preferred alignment as channels that transiently dilated, suspending detrital clasts and allowing them to rotate into flowparallel orientations, similar to the dilation-compaction model of Knipe (1986). As a strain wave migrated along the fault the sediment compacted again, but because of the preferred alignment compaction was more efficient in regions where fluid flow had been channeled. Several examples show the most intense fabric at the margins of fault zones, commonly at lithological junctions. Our observations do not support collapse of the surrounding wall rock as fluid migrated into the permeable fault zone, contrasting with the model of Knipe (1986a). There are narrow branching zones of reduced porosity but the wall rock fabric overall has not collapsed.

Injection of external material along fault zones occurred late, relative to cementation phases. This may have resulted from disaggregation and remobilization of thixotropic sediments some of which would have been likely to occur during rotation of bedding. There is no textural evidence to support the existence of pore-fluid pressures sufficiently high to induce hydrofracturing. Fluid pressures must have been sufficiently high however to facilitate independent particulate flow within the fault zones. An increased proportion of fine grained material in fault zones may indicate that fluid flow velocities were not high enough to transport larger grains above about $10 \mu \mathrm{m}$ diameters. The larger grains may have rotated into alignment during fluid flow or during post-fault compaction. The textural relationships outlined above also indicate that pyrite and carbonate-precipitating fluids permeated faults during deformation. We have found little evidence to suggest that there have been multiple, discrete phases of fluid flow (e.g. crack-seal veins).

\section{RELATIVE TIMING OF FAULTING AND FLUID FLOW}

The heterogeneous and probably diachronous nature of deformation and cementation at Hole $863 \mathrm{~B}$ means that one cementation sequence is unlikely. There are, however, some consistencies in the relative timing of deformation and cementation. Where textural relations between cement phases have been determined, hydrous sulfate phases, zeolites and clay minerals form the earliest cement, followed by calcite, and then pyrite, but we emphasize that the precipitation of these phases overlapped. The timing of early, lithologically controlled cementation and veining relative to the rotation of bedding to its vertical orientation is only loosely constrained. The depth-related diagenetic zoning at this Site suggests that much of the diagenesis post-dated the rotation of bedding planes to their currently steeply dipping positions. Several, early "ghost" veins are oriented perpendicular to bedding, suggesting that these may be pre-rotation dewatering structures formed prior to the rotation of bedding. Some of these ghost veins have been cut by synkinematic calcite (see below). The distribution of early carbonate, pyrite, and zeolite cements was clearly influenced by primary lithological boundaries. For example, in Sample 141-863B-16R-4, 81-85 cm, calcite is located at the junction between a sandstone and silty claystone (Pl. 1). The thickest calcite vein lies at the lithological junction with irregular patches permeating the overlying sandstone. Thinner, dismembered veins are located below in the siltstone.

A close coincidence of normal faulting and carbonate cementation and veining has also been noted in several locations in the core but many veins pre-date at least some of the faulting. This is consistent with the temporal relations of deformation bands and calcite veins observed at Site 860 (Rochford et al., this volume). For example, fragments of calcite and sulfate veins are truncated against discrete lineaments within the shear zones (Pl. 4, Fig. 1). In some sections early carbonate cement has been partially dismembered with only relict cementation remaining and fragments of cement entrained in sediment injected along the fault. In Sample 141-863B-16R-5, 42-48 cm, Fe-sulfide stringers, overprinting a hydrous sulfate phase, are offset by minor normal faults along which clastic material has penetrated (Pl. 5). Similarly in Sample 141-863B-16R-4, 134-136 cm, Fe-sulfide stringers, subparallel to silty laminations, are deflected by the fault. Both normal and reverse faulting have been accompanied by injection of silt and claystone which indicates that the sediments were only partially consolidated. Textural relations suggest that sediment injection is typically one of the latest indicators of fluid mobility in faults, commonly post-dating cementation phases. (Pl. 2).

Fluid flow synchronous with faulting is suggested by the presence of undeformed carbonate veins and pyrite stringer geometries that are geometrically consistent with interpreted fault kinematics. Some calcite veins have been injected parallel to fault margins. Minor strain in the footwall and hanging wall of faults has also influenced the location of fluid flow. For example, in Sample 141-863B-16R-5, 70-73 cm, thin calcite veins have formed in the footwall of the reverse fault ( $\mathrm{Pl}$. 3 , Fig. 5). Branching networks of calcite and ghost veins also accommodate bulk footwall and hanging-wall strain.

Even though Hole 863B is directly overlies the subducted Chile Rise there is little evidence of the impact of an active hydrothermal system on the overlying sediments, although the carbonate veins and pyrite stringers may represent the signature of ridge subduction. The normal faults may relate to coupling or extension caused by topography of the ridge overprinting the accretion-related faults (Behrmann, Lewis, Musgrave, et al., 1992) although extensional fault may also be genetically related to thrusting or slope instabilities. The lack of evidence for high temperature fluid flow that might be expected from ridge impact may be due to the fact that the basal décollement has acted as the primary fluid conduit or that hydrothermal circulation at the ridge is no longer active.

For the spectrum of faults outlined in this study, none of the deformation occurred in completely consolidated material and grain-scale disaggregation is common. The Hole $863 \mathrm{~B}$ sediments clearly illustrate the lack of cohesion that persists at significant depths (up to 800 mbsf) in an accretionary complex. Modeling of cementation fronts, porosity, and permeability needs to takes into account the disaggregation of sediments during deformation and the effect of this disaggregation on bulk sediment cohesion. Contrasting deformation histories and seismic activity will influence both the cementation rates and distribution of cement phases. Wireline logging at Hole 863B suggests that the diagenesis controls the physical property characteristics as a result of the lack of correlation with logged structural features (Behrmann, Lewis, Musgrave, et al., 1992). The fine-scale, distributed, low-strain deformation at Hole 863B may not have significantly affected the physical property data. The results from this study show, however, that fluid flow and faulting are intimately linked and that fine-scale porosity (and permeability?) variations and the cementation history are associated with deformation.

\section{ACKNOWLEDGMENTS}

The support of the Texas A\&M Research Foundation (S. Agar) and NERC (D. Prior) is gratefully acknowledged. A constructive review by $\mathrm{M}$. Langseth and discussions with $\mathrm{K}$. Brown helped to improve this manuscript.

\section{REFERENCES}

Agar, S.M., 1990. The interaction of fluid processes and progressive deformation during shallow level accretion: examples from the Shimanto Belt of SW Japan. J. Geophys. Res., 95:9133-9148.

\footnotetext{
-Abbreviations for names of organizations and publications in ODP reference lists follow the style given in Chemical Abstracts Service Source Index (published by American Chemical Society).
} 
Agar, S.M., Prior, D.J., and Behrmann, J.H., 1989. Back-scattered electron imagery of the tectonic fabrics of some fine-grained sediments: implications for fabric nomenclature and deformation processes. Geology, 17:901-904.

Arch, J., and Maltman, A., 1990. Anisotropic permeability and tortuosity in deformed wet sediments. J. Geophys. Res., 95:9035-9046.

Behrmann, J.H., Lewis, S.D., Musgrave, R.J., et al., 1992. Proc. ODP, Init. Repts., 141: College Station, TX (Ocean Drilling Program).

Borradaile, G.J., 1981. Particulate flow and the generation of cleavage. Tectonophysics, 72:306-321.

Bray, C.J., and Karig, D.E., 1985. Porosity of sediments in accretionary prisms, and some implications for dewatering processes. J. Geophys. Res., 90:768-778.

Brown, K.M., and Behrmann, J., 1990. Genesis and evolution of small-scale structures in the toe of the Barbados Ridge accretionary wedge. In Moore, J.C., Mascle, A., et al., Proc. ODP, Sci. Results, 110: College Station, TX (Ocean Drilling Program), 229-244.

Byrne, T., Maltman, A., Stephenson, E., Soh, W., and Knipe, R., 1993. Deformation structures and fluid flow in the toe region of the Nankai accretionary prism. In Hill, I.A., Taira, A., Firth, J.V., et al., Proc. ODP, Sci. Results, 131: College Station, TX (Ocean Drilling Program), 83-101.

Cande, S.C., Leslie, R.B., Parra, J.C., and Hobart, M., 1987. Interaction between the Chile Ridge and Chile Trench: geophysical and geothermal evidence. J. Geophys. Res., 92:495-520.

Cowan, D.S., 1982. Deformation of partly dewatered and consolidated Franciscan sediments near Piedras Blancas Point, California. In Leggett, J.K. (Ed.), Trench-Forearc Geology: Sedimentation and Tectonics on Modern and Ancient Active Plate Margins. Geol. Soc. Spec. Publ. London, 10:439-457. , 1985. Structural styles in Mesozoic and Cenozoic melanges in the Western Cordillera of North America. Geol. Soc. Am. Bull., 96:451-462.

Fisher, D., and Byrne, T., 1987. Structural evolution of underthrusted sediments, Kodiak Islands, Alaska. Tectonics, 6:775-794.

, 1990. The character and distribution of mineralized fractures in the Kodiak Formation, Alaska: implications for fluid flow in an underthrust sequence. J. Geophys. Res., 95:9069-9080.

Fry, N., 1979. Density distribution techniques and strained length methods for determination of finite strains. J. Struct. Geol., 1:221-229.

Karig, D.E., 1990. Experimental and observational constraints on the mechanical behavior in the toes of accretionary prisms. In Knipe, R.J., and Rutter, E.H. (Eds.), Deformation Mechanisms, Rheology and Tectonics. Geol. Soc. Spec. Publ. London, 54:383-398.

Kemp, A.E.S., 1990. Fluid flow in "vein structures" in Peru forearc basins: evidence from back-scattered electron microscope studies. In Suess, E., von Huene, R., et al., Proc. ODP, Sci. Results, 112: College Station, TX (Ocean Drilling Program), 33-41.

Knipe, R.J., 1986a. Faulting mechanisms in slope sediments: examples from Deep Sea Drilling Project cores. In Moore, J.C. (Ed.), Structural Fabric in Deep Sea Drilling Project Cores from Forearcs, Mem.-Geol. Soc. Am., 166:45-54.

1986b. Microstructural evolution of vein arrays preserved in Deep Sea Drilling Project cores from the Japan Trench, Leg 57. In Moore, J.C. (Ed.), Structural Fabric in Deep Sea Drilling Project Cores from Forearcs. Mem.-Geol. Soc. Am., 166:75-87.

Knipe, R.J., Agar, S.M., and Prior, D.J., 1991. The microstructural evolution of fluid flow paths in semi-lithified sediments from subduction complexes. Philos. Trans. R. Soc. London A, 335:261-273.

Lucas, S.E., and Moore, J.C., 1986. Cataclastic deformation in accretionary wedges: Deep Sea Drilling Project Leg 66, southern Mexico, and on-land examples from Barbados and Kodiak Islands. In Moore, J.C. (Ed.), Structural Fabric in Deep Sea Drilling Project Cores from Forearcs. Mem.Geol. Soc. Am., 166:89-103.

Lundberg, N., and Moore, J.C., 1986. Macroscopic structural features in Deep Sea Drilling Project cores from forearc regions. In Moore, J.C. (Ed.), Structural Fabric in Deep Sea Drilling Project Cores From Forearcs. Mem.-Geol. Soc. Am., 166:13-44.

Maltman, A.J., Byrne, T., Karig, D.E., Lallemant, S., Knipe, R., and Prior, D., 1993. Deformation structures at Site 808, Nankai accretionary prism, Japan. In Hill, I.A., Taira, A., Firth, J.V., et al., Proc. ODP, Sci. Results, 131: College Station, TX (Ocean Drilling Program), 123-133.

Moore, J.C., Roeske, S.M., Lundberg, N., Schoonmaker, J., Cowan, D.S., Gonzales, E., and Lucas, S.E., 1986. Scaly fabrics from Deep Sea Drilling Project cores from forearcs. In Moore, J.C. (Ed.), Structural Fabric in Deep Sea Drilling Project Cores From Forearcs. Mem.-Geol. Soc. Am., 166:55-73.

Pickering, K.T., Agar, S.M., and Prior, D.J., 1990. Vein structure and the role of pore fluids in early wet sediment deformation, late Miocene volcaniclastic rocks, Nuira Group, SE Japan. In Knipe, R.J., and Rutter, E.H., (Eds.), Deformation Mechanisms, Rheology and Tectonics. Geol. Soc. Spec. Publ. London, 54:417-430.

Prior, D.J., and Behrmann, J.H., 1990. Thrust-related mudstone fabrics from the Barbados forearc: a backscattered scanning electron microscope study. J. Geophys. Res., 95:9055-9067.

Sample, J., and Fisher, D., 1986. Duplex accretion and underplating in an ancient accretionary complex, Kodiak Islands, Alaska. Geology, 14:160-163.

Shephard, L.E., and Bryant, W.R., 1983. Geotechnical properties of lower trench inner-slope sediments. Tectonophysics, 99:279-312.

Date of initial receipt: 28 October 1993

Date of acceptance: 4 October 1994

Ms 141SR-016 


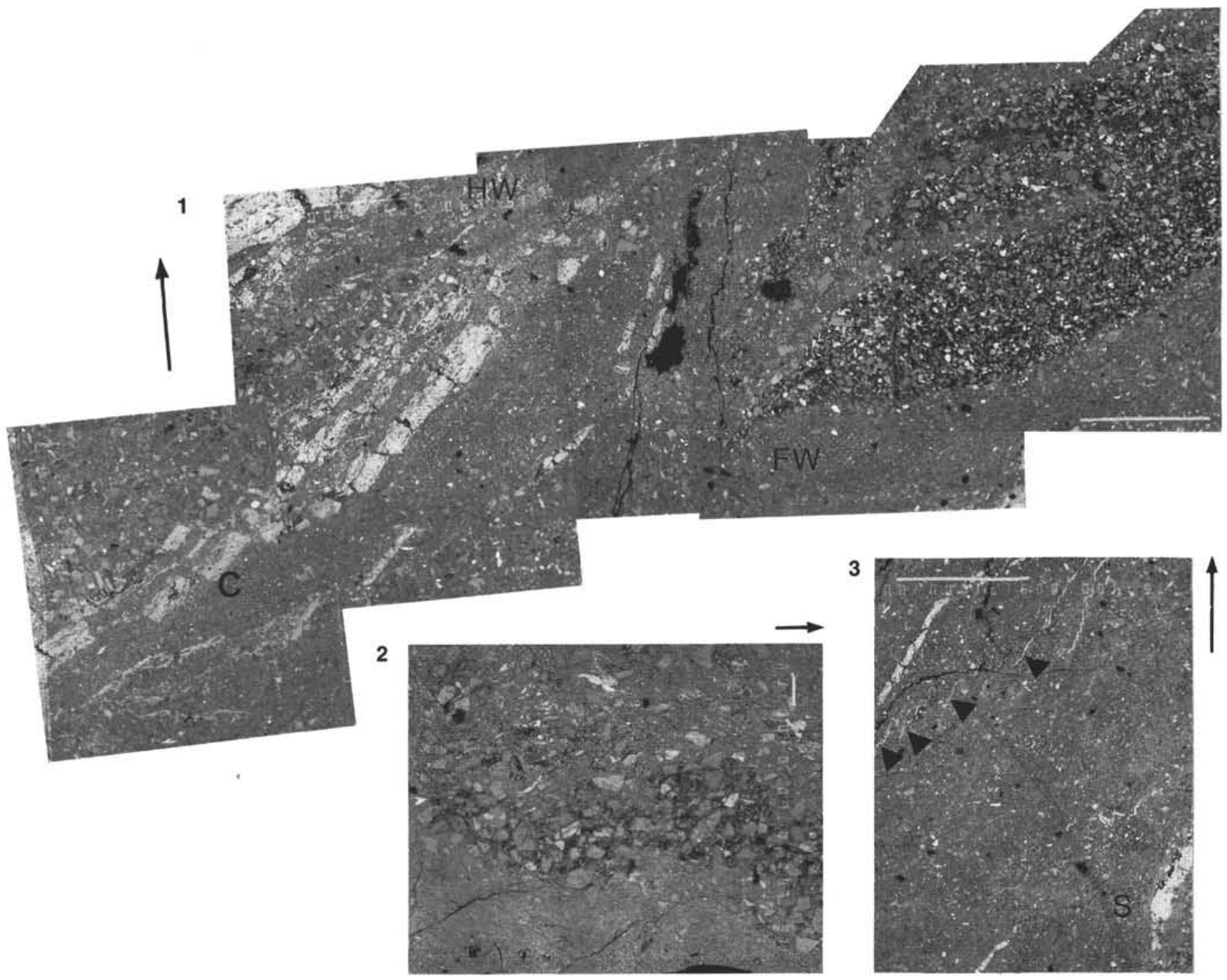

Plate 1. BSE micrographs. Arrows show drill-core orientation. 1. A normal fault in Sample 141-863B-16R-4, $81-85 \mathrm{~cm}$. Hanging wall (HW) of fault is on the left side of the image. Ghost laminae dip from top right to bottom left across the fault zone in the center of the image. In the foot wall (FW), lenses of disrupted sandstone are deflected down into the normal fault. The normal fault zone is about $500 \mu \mathrm{m}$ wide and is oriented subvertically. In the hanging wall, carbonate veins (C) trending subparallel to bedding are deformed by fractures and minor faults oriented at a high angle to the normal fault zone. Fragments have rotated anticlockwise on the minor faults. The veins have localized at the junction between a fine-grained sandstone and an underlying siltstone in the hanging-wall. Scale bar is $1 \mathrm{~mm}$. 2. Disaggregated sandstone lens in footwall of the normal fault in Figure 1. Note the increased porosity in the coarser sandstone layer resulting from the fault-related disruption. Scale bar is $100 \mu \mathrm{m}$. 3. En echelon sigmoidal carbonate veins are located within the normal fault zone in Figure 1. These veins post-date the overlying deformed carbonate vein in the hanging wall. The opening direction of the en echelon vein array (arrows) is subhorizontal in this image and the tapered vein tips are oriented parallel to the fault zone margins. These kinematic indicators are compatible with the normal shear sense implied by the deflection of sandstone lenses in the footwall (Fig. 1). A dark zone that extends from top left to bottom right is filled with a hydrous sulfate cement (S). This structure is interpreted as an early dewatering structure that migrated along a path at high angles to bedding, probably when bedding was horizontal. The carbonate veins cut this dark zone but do not cause a significant offset. The dark zone is truncated by minor faults within the normal fault zone (not shown). Scale bar $=1 \mathrm{~mm}$. 
1

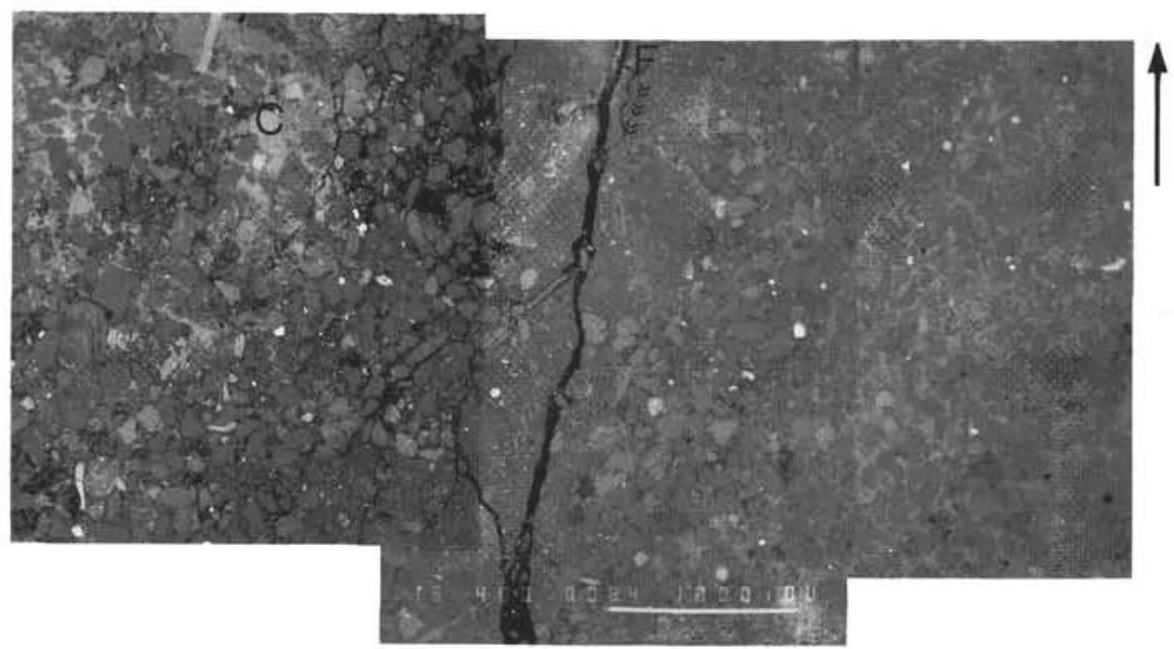

2

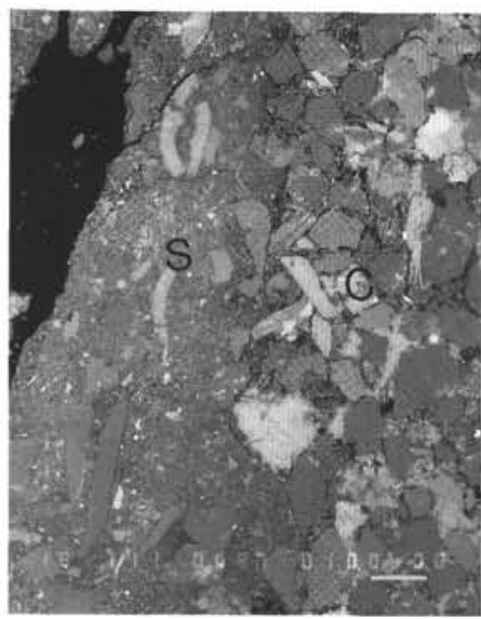

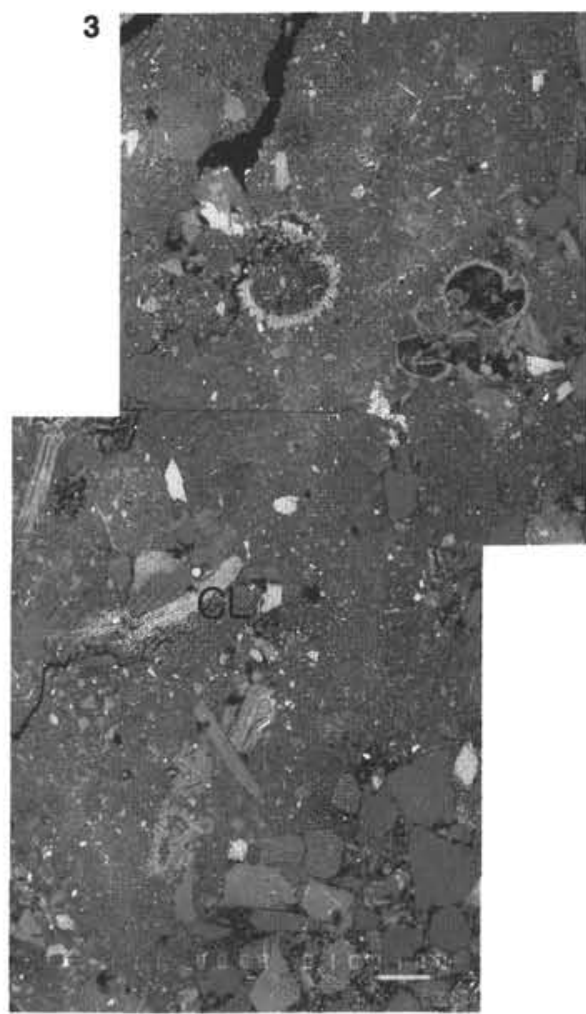

Plate 2. BSE micrographs. Arrow shows drill-core orientation. 1. Fault subparallel to bedding in Sample 141863B-16R-4, 134-136 cm. The fault ([F] $500 \mu \mathrm{m}$ wide) deforms a fine-to-medium-grained sandstone, cemented by carbonate (bright phase $[\mathrm{C}]$ ). Silt and clay grains, injected along the fault have transported fossil fragments and sand grains derived from the wall rock. Disaggregation of the sandstone occurs within $500 \mu \mathrm{m}$ to $1 \mathrm{~mm}$ of the injected zone, grading laterally into carbonate-cemented regions (see right hand side). Zeolites are also present as cement phases. Scale bar $=1 \mathrm{~mm}$. 2. Detail of injected fault zone. Shell fragments (S), suspended in the silty-clay matrix have been transported along the fault zone and aligned subparallel to the fault margins. Inequant detrital grains detached from the wall rock have also aligned subparallel to the fault margins. Carbonate cement between grains in the wall rock is evident as a bright phase (C). Scale bar $=1 \mathrm{~mm}$. 3. Detail of injected fault zone that does not display a preferred orientation of transported clasts. The fault splays at this location, about $2 \mathrm{~cm}$ farther above Figure 1 , broadening the disaggregation zone. Detrital chlorite books (CL) have been kinked around grains either as a result of post-fault compaction or an original depositional fabric retained after disaggregation. The varying backscatter intensities within the fault zone reflect variations in porosity and the uneven distribution of a hydrous sulfate cement (brighter, fine-grained regions have a lower porosity). Scale bar $=1 \mathrm{~mm}$. 

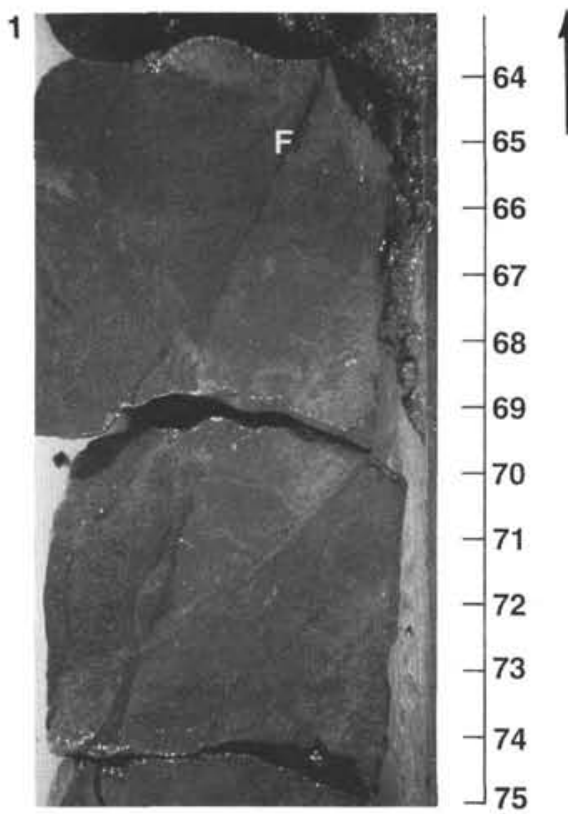

2

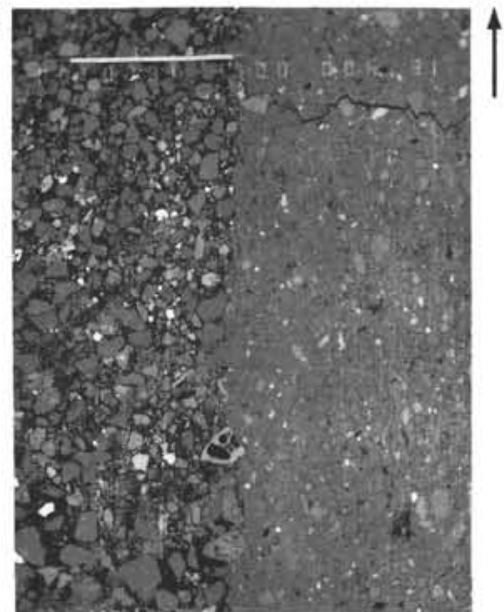

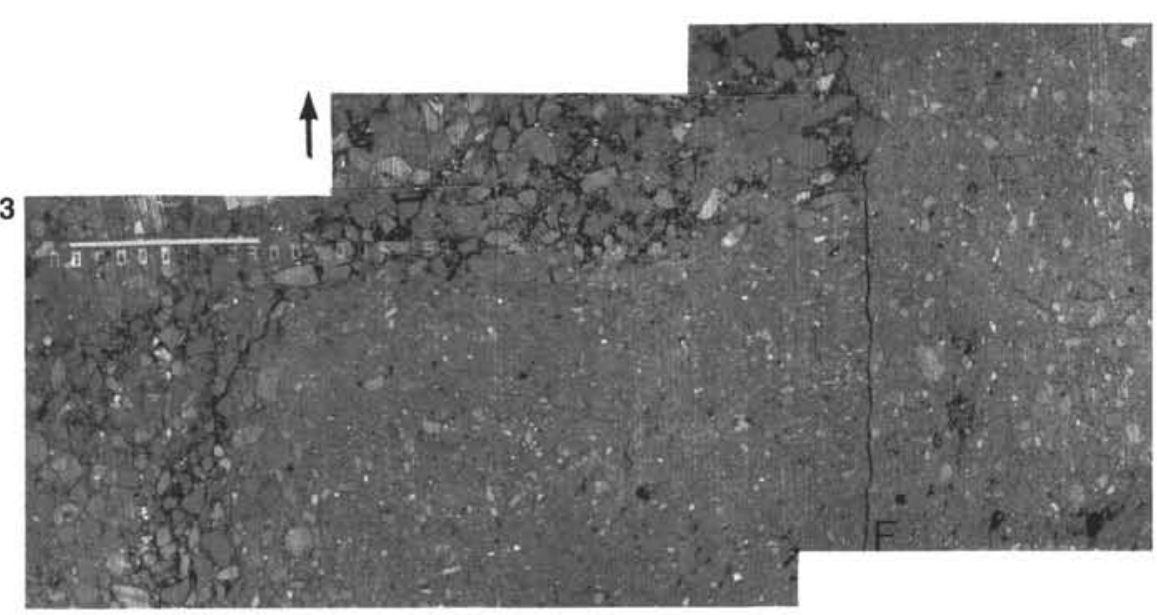

4

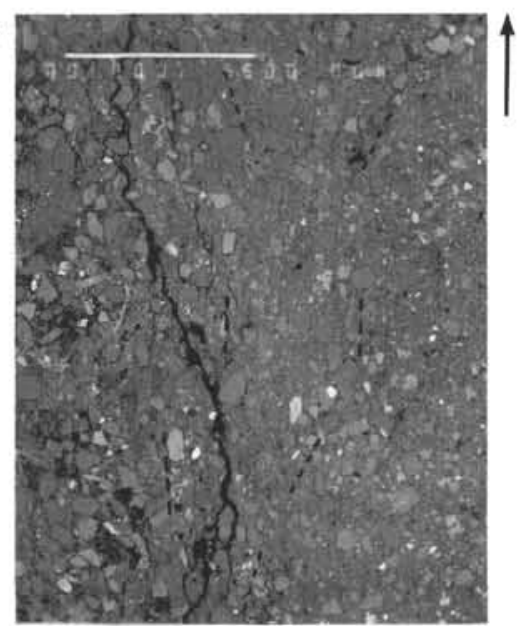

5

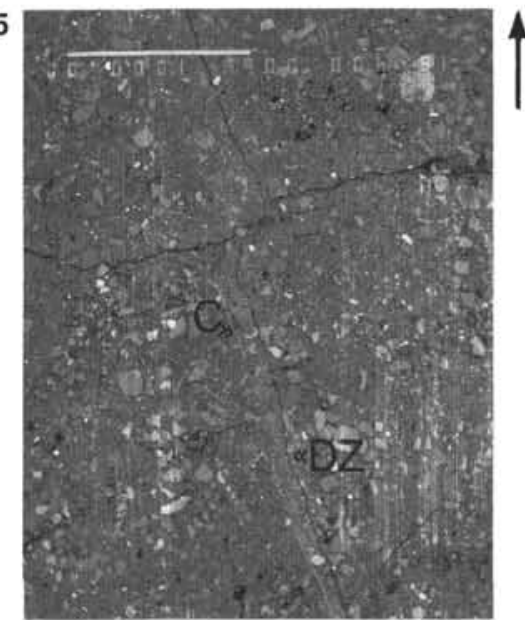

Plate 3. Core photograph and four BSE micrographs of a fault in Section 141-863B-16R-4 located between sandstone and siltstone. Arrow shows way-up of drill-core orientation. 1. The fault is oriented parallel to the steeply-dipping bedding and is delineated by a dark irregular seam (F). Both the footwall and the hanging wall of the fault are dissected by dense fracture arrays. 2. Discrete, planar junction at lithological contact showing little evidence of sediment disturbance although the junction is adjacent to faulted regions in Figures 3 and 4 , along the same fault plane. A slight decrease in open-fracture spacing occurs within the siltstone toward the faulted junction and the porosity of the sandstone increases towards the fault. Scale bar $=1 \mathrm{~mm}$. 3. Disrupted siltstone/sandstone boundary. No clear indicators of shear sense are present. On the right hand side an open fracture is located at a fault $(\mathrm{F})$ along which the siltstone has thickened. We interpret the thickening of the siltstone to have resulted from steep reverse faulting pushing the siltstone into the overlying, partially consolidated sandstone, which has disaggregated around the margins (left-hand side and upper left of image). In this case the left hand side would have moved up relative to the right hand side of the image. Scale bar $=1 \mathrm{~mm}$. 4. Grain-shape alignment in the fault zone. On the left hand side the fine grained sandstone has disaggregated but toward the contact with the siltstone sand grains have rotated subparallel to the fault. Note that the sandstone on the left-hand side of the image has a higher porosity than the adjacent "fault rock." The siltstone lies on the right hand side of the image. Dashed lines show the approximate boundaries of the fault zone. Scale bar $=1 \mathrm{~mm}$. 5. Examples of light anastomosing, cemented zones ([DZ] approximately $100 \mathrm{~m}$ ) in the footwall of the interpreted reverse fault. Open cracks that probably formed during sample preparation run parallel to the cemented zones. The steeply dipping crack also parallels a thin carbonate vein (C) on the left hand side (see also Pl. 4, Fig. 3). These zones form branching networks throughout much of the sediment adjacent to faults. They are interpreted as distributed, minor dilation zones accommodating bulk strain. Scale bar $=1 \mathrm{~mm}$. 
1

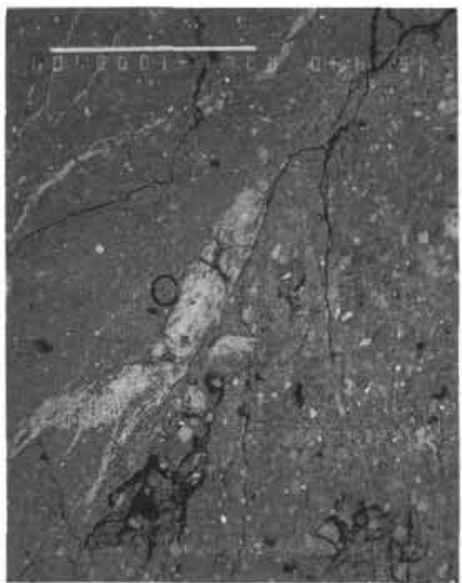

4

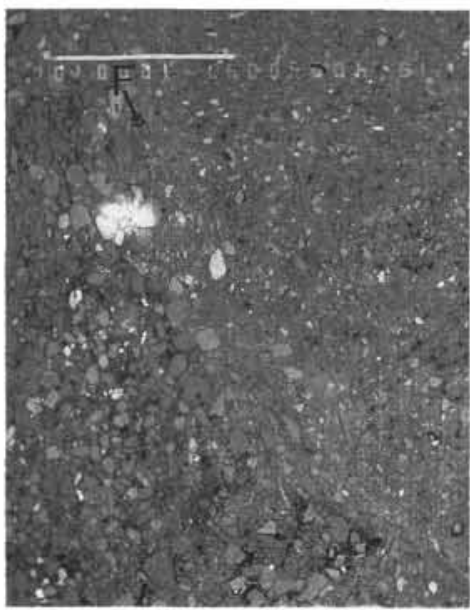

2
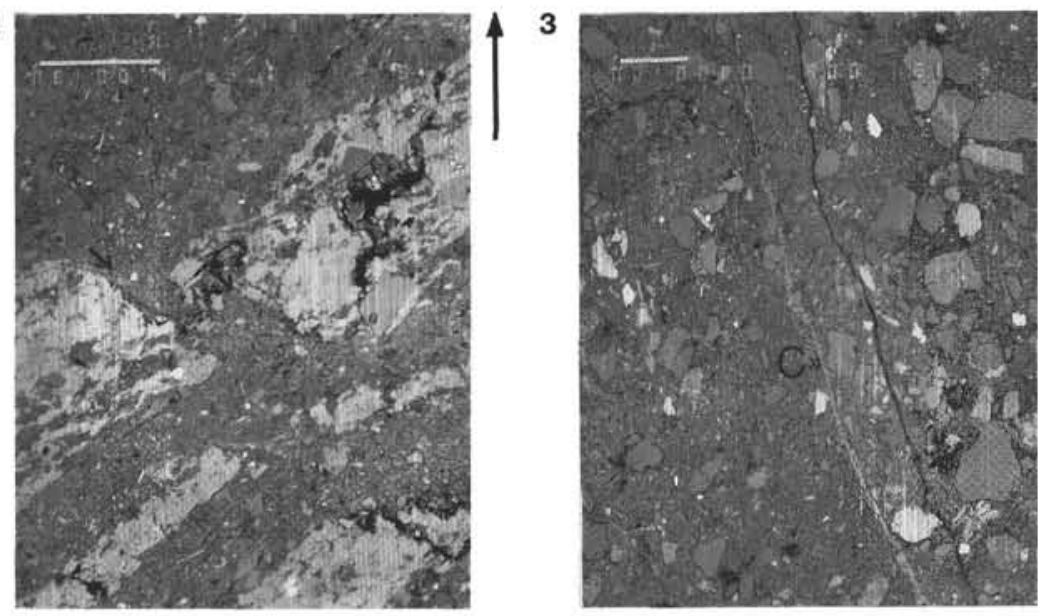

5

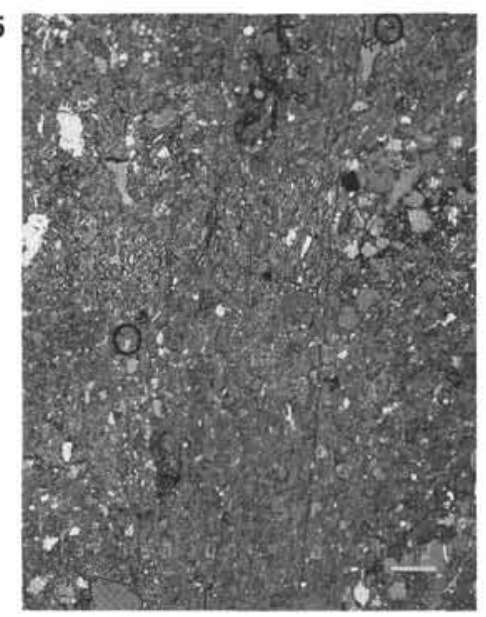

6

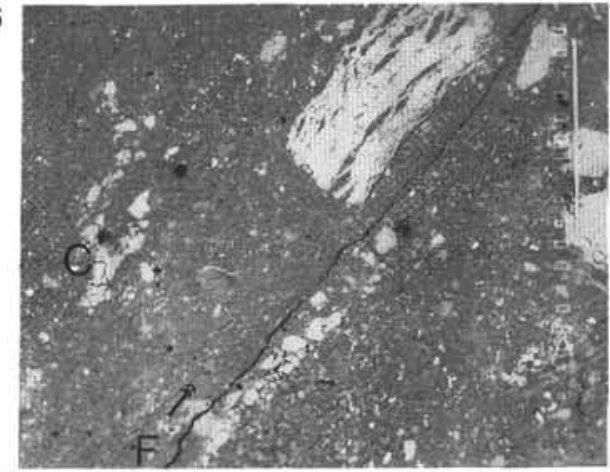

Plate 4. BSE micrographs. Arrow shows drill-core orientation for Figures 1-5. 1. Patchy carbonate cementation and veins dismembered in fault zone in Sample 141-863-16R-4, 81-85 cm. Carbonate vein (C) in center lies subparallel to normal fault, which dips from top right to bottom left. Siltstone has been down-faulted over sandstone. Scale bar $=1 \mathrm{~mm}$. 2. Disruption of carbonate vein with silt and clay grains injected up between the fragments in Sample 141-863-16R-4, 81-85 $\mathrm{cm}$. Arrows indicate normal displacement across zone of injected sediment (see also PI. 1, Fig. 1). Scale bar is $100 \mu \mathrm{m}$. 3. Detail of Plate 3, Fig. 5. A thin carbonate vein runs subparallel to an overlying, thin zone with higher BSE intensity. X-ray dot maps (not shown) suggest that this zone has an increase in Calcium content relative to the surrounding sediment. The right hand side of the zone is delineated by the open fracture. Migration of fluid to the right of the carbonate vein during vein injection may have generated more microcrystalline calcite in cement phases. Scale bar $=100 \mu \mathrm{m} . \quad \mathbf{4}$. Local compaction zone associated with minor reverse faulting at the junction of sandstone and siltstone in Sample 141-863B-16R-4, 70-73 cm. The fault (F) trends from top left to bottom right and displays a weak preferred alignment of sand grains subparallel to the margins. Scale bar $=1 \mathrm{~mm}$. 5. Variations in open-fracture intensity in Sample 141-863B-16R-4, 70-73 cm. Stress release during coring or sample preparation probably generated these fractures, reflecting differential consolidation during and after deformation. The central zone of the image is a minor fault $(\mathrm{F})$ about $500 \mu \mathrm{m}$ wide. A continuous open fracture $(\mathrm{O})$ delineates the right hand margin of the fault. The open fractures may represent the low-strain equivalents of scaly fabric observed in other DSDP and ODP sediment cores from forearcs (Agar et al., 1989; Prior and Behrmann, 1990). Scale bar $=100 \mu \mathrm{m}$. 6. Rotation of fossil fragment subparallel to fault zone in a section perpendicular to the core axis in Sample 141-863-16R-4, 81-85 cm. Pre-existing carbonate cement has been fractured and dispersed in the fault zone. The right hand margin of the fault zone is again delineated by an open fracture with an adjacent trail of carbonate cement. The BSE intensity variations in the fault zone reflect porosity variations. Scale bar $=1000 \mu \mathrm{m}$. 


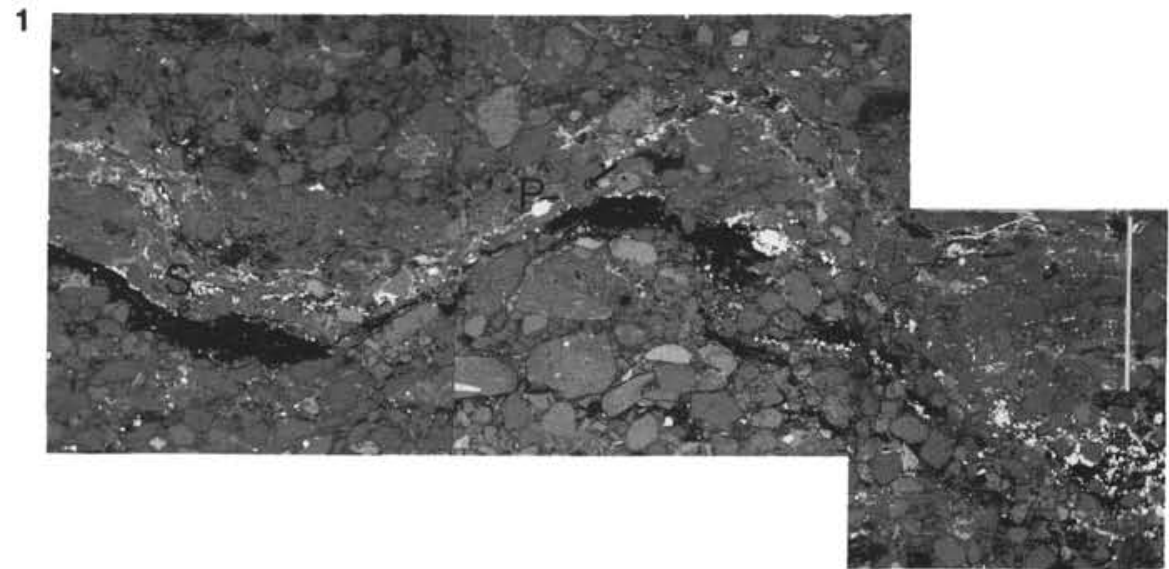

2

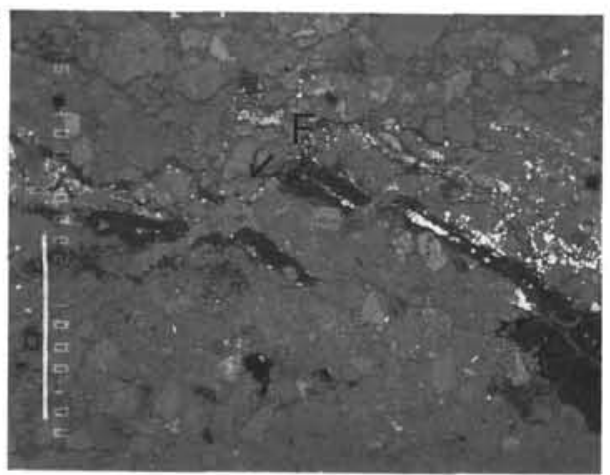

3

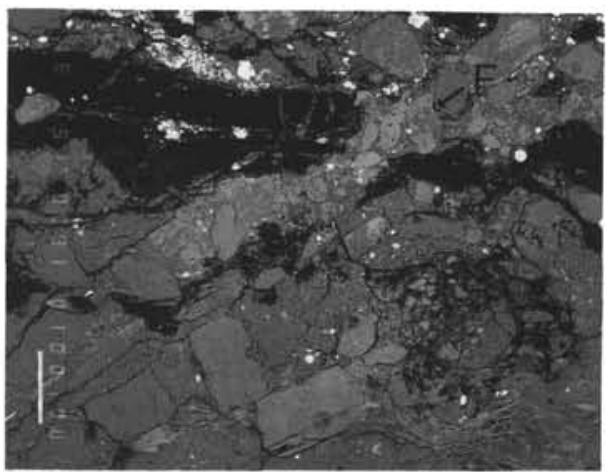

Plate 5. BSE micrographs of normal faulting in Sample 141-863B-16R-5, 42-48 cm. 1. An early-formed hydrous sulfate vein ([S] dark) overprinted by pyrite framboids ([P] bright), precipitated subparallel to steeply dipping bedding. The section is perpendicular to the yertical core axis. The veins and pyrite were faulted by an array of minor normal faults (displacements 1-2 mm). Normal fault trends from top right to bottom left (arrow). 2-3. Faults (F) contain mobilized sediment that separates the cement layers but there is no evidence of intragranular cracking or cataclasis. Normal faulting may be related to early flattening during consolidation of sediments, but it could also be related to oblique normal slip at later stages. 